\title{
Validation and setting up quality control for characterization of aluminum alloys in non-ferrous fraction of auto-shredders
}

\author{
Maria A. Trancoso ${ }^{1} \cdot$ Carlos Nogueira $^{2} \cdot$ Sandra Calisto $^{1}$
}

Received: 7 May 2020 / Accepted: 17 September 2020 / Published online: 3 October 2020

(c) Springer Nature Switzerland AG 2020

\begin{abstract}
The improvement of recycling rates of metal waste, namely those of end-of life vehicles, is nowadays becoming imperative. Aluminum and its alloys are the main metal components in non-ferrous fraction of auto-shredders separated out after sampling. Silicon, Mg, $\mathrm{Cu}, \mathrm{Zn}, \mathrm{Mn}, \mathrm{Ti}, \mathrm{Fe}$ and $\mathrm{Cr}$ are alloying elements, which allowed the identification and differentiation of Al alloys. Flame Atomic Absorption Spectrometry was used for quantification after $\mathrm{HCl}-\mathrm{HNO}_{3}$ digestion, with the exception of $\mathrm{Si}$, where $\mathrm{HCl}-\mathrm{HNO}_{3}-\mathrm{HF}-\mathrm{H}_{3} \mathrm{BO}_{3}$ digestion was used. Performance characteristics of measurement procedures, namely analytical dynamic ranges, limits of detection and quantification, precision and trueness were evaluated and measurement uncertainty estimated by applying an approach based on precision and trueness validation studies and quality control data. Target values, for repeatability, intermediate precision, trueness (recovery) and measurement uncertainty, were specified to differentiate Al alloys based on their own fit-for-purpose. Metrological traceability of the measurements results of the alloying elements was established by using certified values of British Chemical Standard (BCS) of Al alloys, BCS no 181/1, BCS № 268. BCS № 300 and Standard Reference Material of Al-base alloy, SRM 87. The quantification of $\mathrm{Si}, \mathrm{Mg}, \mathrm{Cu}, \mathrm{Zn}, \mathrm{Mn}, \mathrm{Ti}, \mathrm{Fe}$ and $\mathrm{Cr}$ in aluminum alloys from the non-ferrous fraction of automatic crushers was determined successfully through the validated procedures.
\end{abstract}

Keyword Aluminum alloys · Validation · Uncertainty · Traceability · Target · Intermediate precision · Recovery

\begin{tabular}{llll}
\multicolumn{2}{l}{ Abbreviations } & Max & Maximum \\
AA & Atomic absorption & Min & Minimum \\
BCS & British chemical standard & MU & Measurement uncertainty \\
CQC & Calibration quality coefficients & NIST & National Institute of Standards and \\
CRM & Certified reference material & & Technology \\
CS & Calibration standards solutions & PTFE & Polytetrafluoroethylene \\
D2 & Deuterium lamp & QC & Quality control standards solutions \\
DS & Difference of the squared residual stand- & SI & International System of Units \\
& ard deviations of linear and second order & SRM & Standard Reference Material \\
& functions & TV & Testing value for linearity evaluatio \\
ERM & European Reference Materials & List of symbols \\
FAAS & Flame atomic absorption spectrometry & $A_{j}^{\text {rel }}$ & Relative amplitudes of j duplicate \\
IUPAC & International Union of Pure and Applied & $B_{c}$ & Calibration blank (absorbance) \\
& Chemistry & $B_{\text {dig }}$ & Digestion blank (absorbance) \\
n.d. & Not detected & \multicolumn{2}{c}{}
\end{tabular}

$\triangle$ Maria A. Trancoso, maria.trancoso@Ineg.pt | 1 Unidade de Bioenergia e Biorrefinarias, Estrada do Paço do Lumiar, Laboratório Nacional de Energia e Geologia, LNEG, Ed. E - $1^{\circ}, 1649-038$ Lisboa, Portugal. ${ }^{2}$ Unidade de Materiais para a Energia, Laboratório Nacional de Energia e Geologia, LNEG, Ed. C - 1, 1649-038 Lisboa, Portugal. 
$F \quad$ One-sided critical value of the Fisher-Snedecor distribution $(p=0.99)$

$F_{\text {dil }}$

K

$P$

$m$

N

$n$

$\frac{R}{R}$

$\bar{R}_{\gamma}$

$\bar{R}_{C R M}$

$s\left(A_{j}^{r e l}\right)$

$s_{I P}^{\text {rel }}$

$S_{I P(t g)}^{r e l}$

$s^{r e l}$

$s_{Q C(t g)}^{r e l}$

$s_{r}^{r e l}$

$S_{r(t g)}^{r e l}$

$s_{\bar{R}}$

$S_{y 1}$

$s_{y 2}$

$t_{\text {cal }}$

$u_{c}^{\text {rel }}(w)$

$u(\bar{R})$

$u\left(s_{\mid P}^{\text {rel }}\right)$

$u\left(w_{\text {CRM }}\right)$

$u\left(\bar{w}_{\mathrm{CRM}}^{\mathrm{obs}}\right)$

$U$

$U_{\Delta}$

$\checkmark$

$w$

$W_{C R M}$

$\bar{w}_{C R M}$

$y_{i}$

$\gamma_{\text {LOD }}$

$\gamma_{\text {LOQ }}$

$\gamma_{M}$

Dilution factor for the digestion solution in order to bracket the calibration curve.

Coverage factor

Probability of approximately $95 \%$

Mass of sample taken for analysis (g)

Number of calibration data pairs

Number of participants

Recovery

Mean recovery from spiked digestion

solutions

Mean recovery estimated from CRM analysis

Standard deviation $(\mathrm{g} / 100 \mathrm{~g})$

Relative standard deviation of $A_{j}^{\text {rel }}$

Relative standard deviation in intermediate precision consitions

Target value of $s_{\mid P}^{\text {rel }}$

Relative standard deviation of QC

Target value of $s_{O C}^{\text {rel }}$

Relative standard deviation, in repeatability conditions

Target value of $s_{r}^{\text {rel }}$

Standard deviation of $\bar{R}$

Residual standard deviation for linear function $\left(\mathrm{mg} \mathrm{L}^{-1)}\right.$

Residual standard deviation for second order function $\left(\mathrm{mg} \mathrm{L}^{-1}\right)$

Significant statistic test

Relative combined standard uncertainty of $w$

Standard measurement uncertainty of $\bar{R}$

Standard measurement uncertainty of $s_{I P}^{\text {rel }}$

Standard measurement uncertainty of $w_{C R M}$ ( $\mathrm{g} / 100 \mathrm{~g})$

Standard measurement uncertainty of $\bar{w}_{C R M}^{o b s}$

( $\mathrm{g} / 100 \mathrm{~g})$

Expanded uncertainty

Expanded uncertainty of $\Delta(\mathrm{g} / 100 \mathrm{~g})$

Volume of the sample digestion solution $(\mathrm{mL})$

Mass fraction of the metal $(\mathrm{g} / 100 \mathrm{~g})$

Certified mass fraction of CRM $(\mathrm{g} / 100 \mathrm{~g})$

Mean of observed results from CRM analysis

$(\mathrm{g} / 100 \mathrm{~g})$

Absorbance value for ith standard solution

Limits of detection in the digestion solutions $\left(\mathrm{mg} \mathrm{L}^{-1}\right)$

Limit of quantification in the digestion solutions $\left(\mathrm{mg} \mathrm{L}^{-1}\right)$

Mass concentration of the element on the digestion solution $\left(\mathrm{mg} \mathrm{L}^{-1}\right)$
$\gamma_{\mathrm{M}+\mathrm{sp}} \quad$ Mass concentration of the element plus analyte spike on the digestion solution $\left(\mathrm{mg} \mathrm{L}^{-1}\right)$

$\gamma_{\mathrm{sp}} \quad$ Mass concentration of analyte spike added to the digestion solution $\left(\mathrm{mg} \mathrm{L}^{-1}\right)$

$\gamma_{\mathrm{QC}} \quad \mathrm{QC}$ mass concentration $\left(\mathrm{mg} \mathrm{L}^{-1}\right)$

$\hat{y}_{i} \quad$ Absorbance of the standard concentration xi interpolated from the calibration function

$\Delta$

\section{Introduction}

Light alloys, namely aluminum and, more recently, magnesium alloys, have been progressively used in many equipment's such as vehicles, aiming reducing weight and fuel consumption. The driving forces for replacing classic alloys (namely those steel-based) for such new ones have been not only an economic but also an environmental task, trying to save resources and decreasing emissions [1-3]. The improvement of recycling rates of metal waste, namely those from end-of life vehicles, is nowadays becoming imperative because they constitute an important waste stream.

Aluminum and its alloys are the main metal components in non-ferrous fraction of auto-shredders, which also contains copper, brass, stainless steel, zinc and eventually magnesium. The use of light alloys in automotive applications, mainly aluminum but also magnesium, has been progressively increasing. Such alloys shall be recycled, at the end-of-life, due to environment and economic reasons, since recycling of aluminum provides much lower energy consumption than its extraction from primary resources. A major issue in recycling schemes is the separation of wrought and cast alloys, mainly based on the silicon content. Moreover, additional differentiation of alloys by the contents of some target elements would be advisable. Sorting aluminum alloys based on its chemical composition can be a reliable approach to improve efficiency and aluminum recycling rates in this type of waste [3]. Silicon, $\mathrm{Mg}, \mathrm{Cu}, \mathrm{Zn}, \mathrm{Mn}, \mathrm{Ti}, \mathrm{Fe}$ and $\mathrm{Cr}$ are the relevant elements selected (alloying elements) to differentiate Al alloys. For instance, silicon is a good example of an alloying element for sorting Al alloys in non-ferrous auto-shredder fractions by its chemical content, since many alloys have different Si content [2].

In the project Shreddersort, an automated sorting technology was developed, allowing the separation of some Al alloy classes, based on two main techniques, the electromagnetic tensor spectroscopy (EMTS) and the laser induced breakdown spectroscopy (LIBS), as described elsewhere [1, 2]. As starting point for the technology development, a complete and accurate chemical analysis of the aluminum scrap was mandatory, in order to identify the 
main Al alloy series present. Such identification was performed based on the content of specific elements, such as Si for differentiating cast and wrought alloys, as a first step. Identification of main series was achieved by the content of other elements. Examples are, for wrought alloys, the Mg content (in 5000 and 6000 series), the Mn content (in 3000 series) and the very low content of all the alloying metals in 1000 series. In cast alloys, besides de characteristic high Si content, the differentiation of some series was also possible, the most common being the 300 series from their copper content.

The experimental characterization plan was based on the collection of random and representative scrap samples from four vehicle recycling companies. Figure 1 shows Examples of shredder aluminium scraps. Non-ferrous fractions were collected by sampling and the materials screened and classified by classes, sub-classes, morphology and fragment size. After that physical analysis, metal pieces from each subclass were chemical characterized using flame atomic absorption spectrometry (FAAS) after appropriate acid digestions. $\mathrm{An} \mathrm{HCl}-\mathrm{HNO}_{3}$ acid mixture for $\mathrm{Mg}, \mathrm{Cu}, \mathrm{Zn}, \mathrm{Mn}, \mathrm{Ti}, \mathrm{Fe}$ and $\mathrm{Cr}$ analysis was used, as described further, while for $\mathrm{Si}$ analysis an adapted digestion with a $\mathrm{HCl}-\mathrm{HNO}_{3}-\mathrm{HF}$ mixture was used, followed by $\mathrm{HF}$ complexation using $\mathrm{H}_{3} \mathrm{BO}_{3}[4,5]$. This fluoric-boric acid matrix has no influence on the absorbance signal for $\mathrm{Si}$, as previously studied [5].

Validation of the measurement procedure, metrological traceability and measurement uncertainty (MU) of the results are the key factors to ensure the quality of the chemical measurements. In according to the vocabulary of international metrology [6] validation is the verification, wherein the specified requirements are adequate for an intended. Metrological traceability is the property of a measurement result whereby the result can be related to a reference through a documented unbroken chain of calibrations, each contributing to the measurement uncertainty wherein $\mathrm{MU}$ is the non-negative parameter characterizing the dispersion of the quantity values being attributed to a measurand, based on the information used [6].

Nowadays, the validation of measurement procedures aims both the evaluation of the performance characteristics and the demonstration that those performances are suitable for the intended use of the results. A single validation approach to determine the metrological characteristic of the measurement procedures selected following Eurachem guidelines [7] for quantitative test for impurities, namely analytical dynamic ranges, calibration functions, limits of detection and quantification; stability control of the calibration functions; evaluation of contamination; matrix effects; precision and trueness. In addition, it was given special attention to measurement uncertainty, besides from MU not being a performance characteristic of a measurement procedure, but a property of the results obtained using that measurement procedure, the validation studies and quality control data comprising the entire analytical procedures. The main uncertainty components are trueness (recovery) and precision (reproducibility within the laboratory), which comprise the systematic and random and errors, respectively.

Precision component in intermediate conditions were calculated associating the repeatability standard deviation from duplicate analysis with ones obtained from the individual control charts of the quality control standards. The trueness component of the overall analytical procedure was obtained from the analysis of different CRM [8-10], namely BCS n० 181/1, BCS № 268, BCS № 300 and SRM87a).

Both measurement uncertainty and measurement traceability of the results give the metrological quality allowing comparability $[11,12]$. To assess measurement
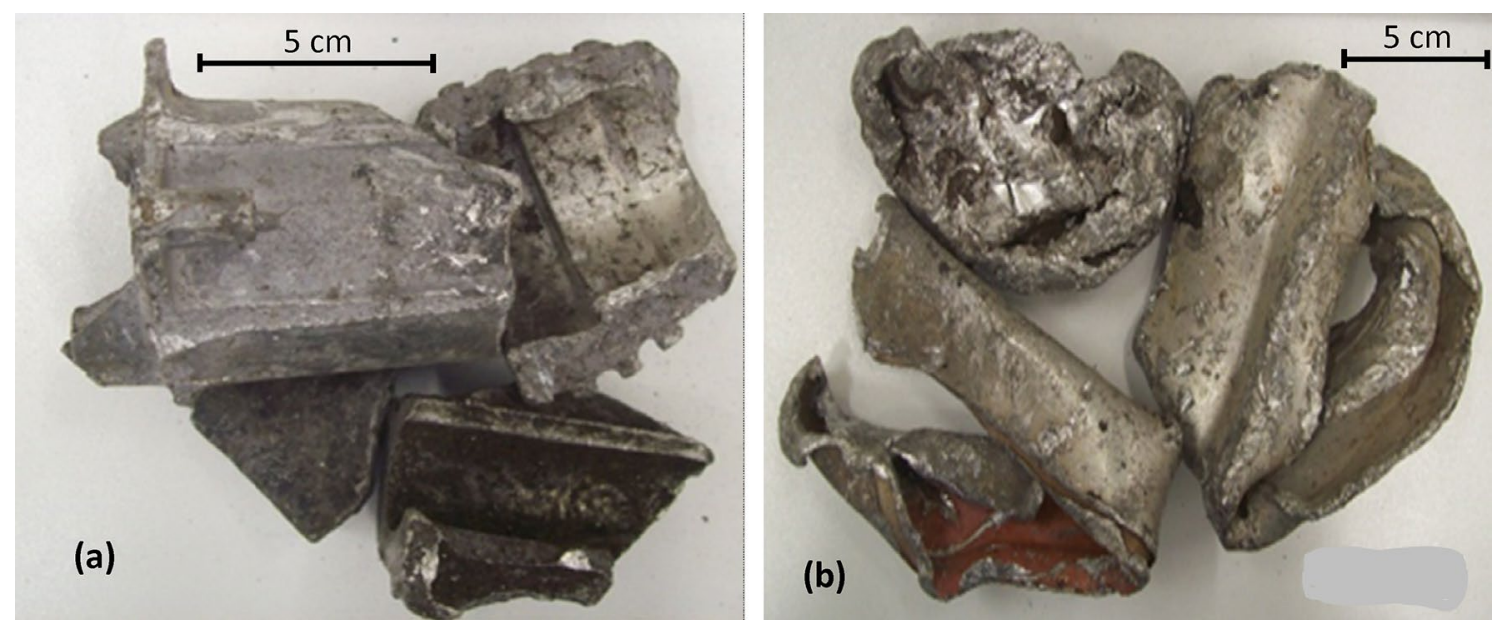

Fig. 1 Examples of shredder aluminium scraps: a cast fragments; $\mathbf{b}$ wrought fragments 
uncertainty for their intended use in the field of this work, information for setting the target MU from regulation, specification or measurement quality requirements was not available. Target values for repeatability, intermediate precision, trueness (recovery) and uncertainty for Al alloys differentiation in non-ferrous fraction of auto-shredders were stated from their own fit-for-purpose. The selection of CRM either for target mass fraction or the matrix matching, contributes to the statement of metrological traceability.

The aim of this paper was to assess the performance characteristics of the measurement procedures used for the chemical characterization of aluminum alloys in nonferrous fraction of auto-shredders and setting up quality control actions. Own fit-for-purposes were set for all performance characteristics of the analytical procedures providing reliable data for differentiating Al alloys.

\section{Experimental}

\subsection{Materials and equipment}

All the reagents were of analytical reagent grade from Merck (Darmstadt, Germany) and all solutions prepared using ultrapure water of $18 \mathrm{M} \Omega \mathrm{cm}^{-1}$ resistivity, supplied from a Millipore Milli-Q water purification system (Millipore, Bedford, MA).

Calibration standard solutions, CS, were prepared from Certipur ${ }^{\circledast}$ reference standard solutions with $1000 \mathrm{mg} \mathrm{L}^{-1}$ for each metal from daily, quality control standard solutions, QC, were prepared just before put into use, spending independent reference standard solutions from Merck (Darmstadt, Germany). Merck solutions have metal contents traceable to the unit $\mathrm{mg} \mathrm{L}^{-1}$ of the
International System of Units (SI) checked through the analysis of the corresponding SRM produced by NIST of the USA.

The CRMs used were: $4 \%$ copper aluminum alloy, BCS $n^{\circ} 181 / 1,5 \%$ silicon aluminum alloy, $B C S n^{\circ} 268$, aluminum alloy BCS no 300 from British Chemicals and a siliconaluminum alloy, SRM 87a from the National Bureau of Standards.

All samples were dried into a Heraeus drying oven at $105^{\circ} \mathrm{C}$, after washing. A calibrated AT 200 Mettler balance was used for all weighing's. Volume measurements were taken using volumetric equipment of class $A$ and As.

Alloying metals were determined by FAAS using a Solar 969 AA Spectrometer (Thermo Elemental, England) equipped with a deuterium lamp for the background correction, selecting each most intense line as manufacture recommendations [13]: Table 1 shows the optimized operational conditions. The instrument was operational whenever the absorbance of a standard solution did not differ more than $20 \%$ of the manufacturer's recommended values $[11,12]$.

Calibrations were performed at six levels, including a calibration blank, $B_{C}$, covering the mass concentration ranges (Table 2). The CS and QC measurement solutions were prepared for $\mathrm{Mg}$ in $\mathrm{HCl} 0.5 \mathrm{~mol} \mathrm{~L}^{-1}$ solution containing $6 \mathrm{~g} \mathrm{~L}^{-1}$ of $\mathrm{La}_{2} \mathrm{O}_{3}$ as releasing agent minimizing oxyanion interferences. Iron and $\mathrm{Mn}$ were determined in $\mathrm{HCl}$ $0.5 \mathrm{~mol} \mathrm{~L}^{-1}$ solution with $50 \mathrm{mg} \mathrm{L}^{-1}$ of $\mathrm{Ca}$ to avoid chemical interferences [14]. In case of $\mathrm{Cu}, \mathrm{Zn}, \mathrm{Si}, \mathrm{Ti}$ and $\mathrm{Si}$ the standards were prepared in $0.5 \mathrm{~mol} \mathrm{~L}^{-1} \mathrm{HNO}_{3}$ solution containing $2 \mathrm{~g} \mathrm{~L}^{-1}$ of $\mathrm{KCl}$ only for $\mathrm{Si}$, Ti and $\mathrm{Cr}$ to overcome those ionization interferences. No matrix matching due to $\mathrm{HF}-\mathrm{H}_{3} \mathrm{BO}_{3}$ acid was required, as previously studied [5]. Each absorbance values were the average of three absorbance readings with $3 \mathrm{~s}$ of integration time.

Table 1 Operational conditions for FAAS

\begin{tabular}{|c|c|c|c|c|c|c|c|}
\hline \multirow[t]{2}{*}{ Element } & \multirow[t]{2}{*}{ Wavelength $(\mathrm{nm})$} & \multicolumn{2}{|l|}{ Lamp } & \multirow[t]{2}{*}{ Slit width (nm) } & \multirow{2}{*}{$\begin{array}{l}\text { Background } \\
\text { correction }\end{array}$} & \multirow[t]{2}{*}{ Flame chemistry } & \multirow{2}{*}{$\begin{array}{l}\text { Burner head } \\
(\mathrm{cm})\end{array}$} \\
\hline & & current $(\mathrm{mA})$ & $\begin{array}{l}\% \text { of } \\
\text { maximum } \\
\text { intensity }\end{array}$ & & & & \\
\hline Chromium & 357.8 & 12 & 75 & 0.5 & no & $\mathrm{N}_{2} \mathrm{O} / \mathrm{C}_{2} \mathrm{H}_{2}$-reducing & 5 \\
\hline Copper & 324.8 & 5 & 50 & 0.5 & no & Air/ $\mathrm{C}_{2} \mathrm{H}_{2}$-stoichiometric & 10 \\
\hline Iron & 248.3 & 15 & 75 & 0.2 & $\begin{array}{l}\text { yes } \\
\text { (D2 lamp) }\end{array}$ & Air/ $\mathrm{C}_{2} \mathrm{H}_{2}$-stoichiometric & 10 \\
\hline Magnesium & 285.1 & 4 & 75 & 0.5 & no & Air/ $\mathrm{C}_{2} \mathrm{H}_{2}$-stoichiometric & 10 \\
\hline Manganese & 279.5 & 12 & 75 & 0.2 & no & Air/ $\mathrm{C}_{2} \mathrm{H}_{2}$-stoichiometric & 10 \\
\hline Silicon & 251.5 & 15 & 75 & 0.5 & $\begin{array}{l}\text { yes } \\
\text { (D2 lamp) }\end{array}$ & $\mathrm{N}_{2} \mathrm{O} / \mathrm{C}_{2} \mathrm{H}_{2}$-reducing & 5 \\
\hline Titanium & 365.3 & 15 & 75 & 0.5 & no & $\mathrm{N}_{2} \mathrm{O} / \mathrm{C}_{2} \mathrm{H}_{2}$-reducing & 5 \\
\hline Zinc & 213.9 & 10 & 50 & 0.5 & $\begin{array}{l}\text { yes } \\
\text { (D2 lamp) }\end{array}$ & Air/ $\mathrm{C}_{2} \mathrm{H}_{2}$-stoichiometric & 10 \\
\hline
\end{tabular}


Table 2 Metrological performance characteristics of calibration functions

\begin{tabular}{lllllll}
\hline Element & $\begin{array}{l}\text { Concentration } \\
\text { range } \\
\left(\mathrm{mg} \mathrm{L}^{-1}\right)\end{array}$ & Absorbance range & $T V$ & $C Q C$ & $\begin{array}{l}\gamma_{\text {LoD }} \\
\left(\mathrm{mg} \mathrm{L}^{-1}\right)\end{array}$ & $\begin{array}{l}\gamma_{\text {LoQ }} \\
\left(\mathrm{mg} \mathrm{L}^{-1}\right)\end{array}$ \\
\hline Chromium $^{\mathrm{a}}$ & $0.1-2$ & $0.01-0.21$ & 7.4 & 0.01 & 0.03 & 0.09 \\
Copper $^{\mathrm{a}}$ & $0.05-1$ & $0.01-0.18$ & 0.4 & 0.01 & 0.006 & 0.02 \\
Iron $^{\mathrm{a}}$ & $0.2-2$ & $0.01-0.20$ & 3 & 0.03 & 0.07 & 0.2 \\
Magnesium $^{\mathrm{b}}$ & $0.01-0.2$ & $0.02-0.30$ & 35 & 0.01 & 0.001 & 0.004 \\
Manganese $^{\mathrm{a}}$ & $0.1-0.6$ & $0.01-0.15$ & 3.7 & 0.02 & 0.02 & 0.05 \\
Silicon $^{\mathrm{a}}$ & $10-80$ & $0.03-0.27$ & 1.2 & 0.02 & 1.7 & 6 \\
Titanium $^{\mathrm{b}}$ & $2-25$ & $0.02-0.12$ & 23 & 0.01 & 0.8 & 2 \\
Zinc $^{\mathrm{a}}$ & $0.02-0.4$ & $0.02-0.29$ & 7.6 & 0.02 & 0.009 & 0.03 \\
\hline
\end{tabular}

$T V$ Testing value for linearity evaluation $\left(T V=D S^{2} / s_{y 2}^{2}\right)$, with $D S^{2}=(N-2) s_{y 1}^{2}-(N-3) s_{y 2}^{2}[15,16]$ CQC $=\sqrt{\frac{\sum_{i}^{N}\left(\frac{\left(y_{i}-y_{i}\right)}{y_{i}}\right)^{2}}{N-1}}[17,18]$

${ }^{\mathrm{a}}$ First-order calibration function

${ }^{\mathrm{b}}$ Second-order calibration function

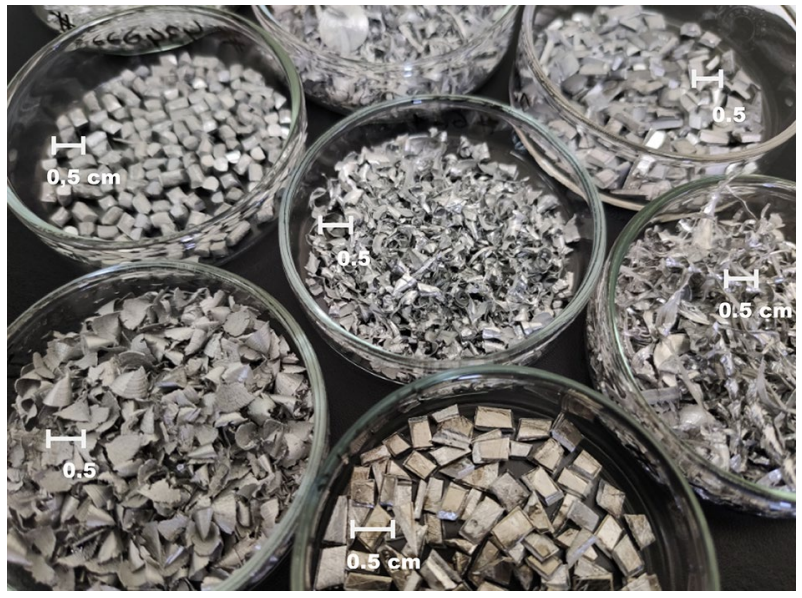

Fig. 2 Examples of samples of smaller fragments suitable for analysis, obtained from raw fragments (as depicted in Fig. 1) after surface cleaning, cutting/drilling until average size lower than $0.5 \mathrm{~cm}$

\subsection{Sample preparation and acid digestions}

To avoid chemical contamination, mechanically, the fragment surfaces of the samples, were cleaned, cuted and drilled in smaller fragments suitable for analysis, as shown in Fig. 2. Afterwards, it was washed all samples and CRM with ethanol followed by ultrapure water and drying at $105^{\circ} \mathrm{C}$ before acid decomposition. Two different acid mixtures for solubilisation procedures were considered due to the different behaviour of the elements in acids. An $\mathrm{HCl}-\mathrm{HNO}_{3}$ acid mixture for $\mathrm{Mg}, \mathrm{Cu}, \mathrm{Zn}, \mathrm{Mn}, \mathrm{Ti}, \mathrm{Fe}$ and $\mathrm{Cr}$ analysis and $\mathrm{HCl}-\mathrm{HNO}_{3}-\mathrm{HF}$ mixture followed by $\mathrm{HF}$ complexation using $\mathrm{H}_{3} \mathrm{BO}_{3}$ for silicon $[4,5]$. Following those experimental measurement procedures, perform blank reagent, QC, CRM in duplicate sets.

Figure 2

\subsubsection{Hydrochloric-nitric acid digestion}

Samples and CRM's $(\approx 0.5 \mathrm{~g})$ were weighed into a $250 \mathrm{ml}$ beaker to which $20 \mathrm{~mL}$ of $6 \mathrm{~mol} \mathrm{~L}^{-1} \mathrm{HCl}$ solution was slowly added, followed by $5 \mathrm{ml}$ of $\mathrm{HNO}_{3}$. Those mixtures were gradually heated on a hot plate. Temperature was increased until mixtures gently boiled for 3-5 min to expel the nitrous vapours. After cooling, the solution was transferred into $100 \mathrm{ml}$ volumetric flask with ultrapure water and diluted to the mark. It was let settle overnight and whenever necessary the mixture was filtered before atomic absorption measurements.

\subsubsection{Hydrochloric-fluorohydric-nitric-boric acid mixture digestion}

About $0.2 \mathrm{~g}$ of samples and CRMs were weighed into a covered PTFE beaker. A volume of $5 \mathrm{~mL}$ of $\mathrm{HCl}$ was added dropwise and letting the reaction to diminish between additions. When the reaction has decreased, usually around two hours after, it was slowly added $2.5 \mathrm{~mL}$ of $\mathrm{HF}$, taking care for the mixture temperature did not exceed $50^{\circ} \mathrm{C}$ and stayed overnight. Then, a volume of $3.5 \mathrm{ml}$ of $\mathrm{HNO}_{3}$ was added avowing heating of the mixture. After total decomposition, $8 \mathrm{ml}$ of $50 \mathrm{~g} \mathrm{~L}^{-1} \mathrm{H}_{3} \mathrm{BO}_{3}$ solution was added allowing the mixture to settle for two hours at least. The solution was transferred into a $50 \mathrm{ml}$ volumetric flask and diluted to the mark with ultrapure water. 


\section{Results and Discussion}

The measurand, mass fraction of each metal, $w$, in aluminum alloys, expressed in $[\mathrm{g} /(100 \mathrm{~g}]$ was obtained by Eq. (1) taking into account the influencing factors and another potential sources due to the sample decomposition evaluated as recovery, $R_{\gamma}$.

$w=\frac{10^{-4} \cdot \gamma_{M} \cdot V \cdot \mathrm{F}_{\mathrm{dil}}}{m \cdot R_{\gamma}}$

\subsection{Analytical dynamic ranges}

Atomic absorption spectrometric techniques require the comparison of the absorbance of the sample digestion solution with a set of calibration standard solutions. Table 2 shows both mass concentration and absorbance ranges of the calibration functions which are obtained by regression analysis after evaluation of linearity using Mandel fitting test [15-17] and assuming all errors normally distributed in $y$-axis. For $\mathrm{Mg}$ and $\mathrm{Ti}$ the second order function provide the best fit because the testing values, TV, were lower than the critical Fisher ones, $\mathrm{F}$, while for $\mathrm{Cr}, \mathrm{Cu}$, $\mathrm{Fe}, \mathrm{Mn}$ and Si linear calibration functions were used (TV $<F$ ), as shown in Table 2 . In all situations the critical values of Fisher-Snedecor distribution was $F_{1 ; 4 ; 0.99}=21.2$ and the squared correlation coefficients were higher than 0.998 . Calibration quality coefficients, CQC, were calculated to assess the quality of regression analysis $[17,18]$ and CQC values from 0.01 to 0.03 (Table 2) were obtained confirming the adequacy of the calibration functions models since relative precision up to 0.05 is acceptable in FAAS $[19,20]$.

Limits of detection in the digestion solutions were calculated from both calibration blanks and residual standard deviations, as reported by Miller et al. [21], following IUPAC recommendations $[22,23]$ as previously discussed $[9,12$,
17]. Table 2 reports the $\gamma_{\text {LOD }}$ values showing the lowest concentration of the analytes that can be detected [24]. The $\gamma_{\mathrm{LOQ}}$ values give information about the lowest level of analyte that can be determined with the performance of the calibration curve. In this work $\gamma_{\text {LOQ }}$ values were calculated considering the IUPAC default value of $k=10$ [22-24], being $\gamma_{\mathrm{LOQ}}=3.3 \gamma_{\mathrm{LOD}}$ and they must be equal or lower than the lowest limit of the dynamic range. Table 2 shows that this requirement was always fulfilled. These limits depend on the precision of the regression and are checked using quality control standards.

For warranting the stability of the calibration functions throughout the analysis period, quality control standards solutions, every six sample sets, were analysed. No drift were considered whenever relative errors on $\gamma_{\mathrm{QC}}$ were within \pm 0.05 of the expected values for FAAS with air- $\mathrm{C}_{2} \mathrm{H}_{2}$ flame or \pm 0.10 in case of $\mathrm{N}_{2} \mathrm{O}-\mathrm{C}_{2} \mathrm{H}_{2}$ flame $[11,17]$ due to more flame instability. If $\gamma_{\mathrm{QC}}$ values were outside the measurements then a new calibration was carried out $[11,12$, 17].

Table 3 shows $s_{O C}^{\text {rel }}$ values obtained from the individual control charts. Target values of $s_{Q C^{\prime}}^{r e l}$, were defined considering the acceptance criteria defined and assuming a rectangular distribution. For $\mathrm{Cr}$, Si and $\mathrm{Ti}$ the $s_{Q C(t g)}^{r e l}$ values of 0.058 and $s_{\mathrm{QC}(\mathrm{tg})}^{\mathrm{rel}}=0.029$ for $\mathrm{Cu}, \mathrm{Fe}, \mathrm{Mg}, \mathrm{Mn}$ and $\mathrm{Zn}$ were obtained.

\subsection{Contaminations}

In this work two blanks were produced: the calibration blank, $B_{c}$, and the digestion blank, $B_{d i g}$ carried out in each acid digestion batch. These blanks allow the control of possible contamination resulting from either the reagents or the equipment used during sample processing. In routine analysis, $B_{c}$ absorbance were accepted whenever $B_{c} \leq$ 0.005 for $\mathrm{Cr}, \mathrm{Cu}, \mathrm{Fe}, \mathrm{Mn}, \mathrm{Si}, \mathrm{Ti}, \mathrm{Zn}$ and $B_{c} \leq 0.015$ for $\mathrm{Mg}$. In case of digestion blanks, the $B_{\text {dig }}$ absorbance criteria were
Table 3 Validation and quality report

\begin{tabular}{|c|c|c|c|c|c|c|c|c|c|c|}
\hline \multirow[t]{2}{*}{ Parameter } & \multirow[t]{2}{*}{ Range $[g /(100 g)]$} & \multicolumn{3}{|c|}{ Precision } & \multicolumn{3}{|c|}{ Trueness } & \multirow[b]{2}{*}{$\begin{array}{l}w_{L O Q} \\
\mathrm{~g} / 100 \mathrm{~g}\end{array}$} & \multirow[b]{2}{*}{$u_{c}^{r e l}(w)$} & \multirow[b]{2}{*}{$u_{c_{-} t g}^{r e l}(w)$} \\
\hline & & $s_{r}^{r e l}$ & $s_{Q C}^{r e l}$ & $s_{I P}^{r e l}$ & $\bar{R}_{C R M}$ & $u\left(\bar{R}_{C R M}\right)$ & $t_{c a l}$ & & & \\
\hline $\mathrm{Cr}$ & $0.04-1.6$ & 0.014 & 0.013 & 0.019 & 1.049 & 0.005 & 1.1 & 0.002 & 0.056 & 0.086 \\
\hline $\mathrm{Cu}$ & $0.05-3$ & 0.016 & 0.028 & 0.031 & 1.003 & 0.010 & 0.2 & 0.02 & 0.035 & 0.074 \\
\hline $\mathrm{Fe}$ & $0.3-1$ & 0.022 & 0.042 & 0.044 & 1.002 & 0.006 & 0.1 & 0.11 & 0.048 & \\
\hline $\mathrm{Mg}$ & $0.1-2.5$ & 0.030 & 0.023 & 0.036 & 0.974 & 0.013 & 2.0 & 0.003 & 0.040 & \\
\hline $\mathrm{Mn}$ & $0.004-0.3$ & 0.028 & 0.024 & 0.037 & 0.988 & 0.009 & 0.21 & 0.002 & 0.066 & \\
\hline $\mathrm{Si}$ & $0.1-8$ & 0.020 & 0.021 & 0.029 & 0.996 & 0.013 & 0.21 & 0.15 & 0.034 & 0.086 \\
\hline $\mathrm{Ti}$ & $0.01-0.1$ & 0.034 & 0.053 & 0.063 & 0.960 & 0.012 & 1.6 & 0.26 & 0.064 & \\
\hline $\mathrm{Zn}$ & $0.02-2.1$ & 0.018 & 0.018 & 0.026 & 0.986 & 0.030 & 0.8 & 0.002 & 0.042 & 0.074 \\
\hline
\end{tabular}

$s_{r}^{\text {rel }}$ given by Eq. (2), $\bar{R}_{C R M}$ given by Eq. (6), $u\left(\bar{R}_{C R M}\right)$ given by Eq. (7), $t_{c a l}$ calculated $t$ statistic [25], $u_{c}^{\text {rel }}(w)$ given by Eq. (8), $u_{c_{-} t g}^{r e l}(w)$ given by Eq. (8) 
$B_{\text {dig }} \leq 0.005$ for $\mathrm{Cr}, \mathrm{Fe}, \mathrm{M}$ and $\mathrm{Si}, B_{\text {dig }} \leq 0.020$ for $\mathrm{Mg}$ and $B_{\text {dig }}$ $\leq 0.010$ for $\mathrm{Cu}$ and $\mathrm{Zn}$. These limits are the warning limits of individual control charts. Additionally $\left|B_{d i g}-B_{c}\right| \leq 0.003$. Otherwise, new calibration curves were calculated using the CS absorbance after subtracting the $B_{c}$ values. In such cases $\gamma_{M}$ values were recalculated using the absorbance deducted from the $B_{\text {dig }}$ value (1716).

\subsection{Matrix effects}

The assumption that no matrix effect in calibration function due to the matrix difference between calibration solutions and digestion solutions was evaluated by spiking digestion solutions with known amounts of analyte. Whenever the target recovery is inside the interval $(1.00 \pm 0.10)$ that requirement is fulfilled. As can be seen in Table 3 no matrix effects were found for $\mathrm{Cr}\left(\mathrm{F}_{\mathrm{dil}}=1\right), \mathrm{Cu} \geq\left(\mathrm{F}_{\mathrm{di}} 50\right), \mathrm{Mn}$ ( $\left.F_{\text {dil }} \geq 10\right) ; M g\left(F_{\text {dil }} \geq 10\right), \operatorname{Si}\left(F_{\text {dil }}=1\right)$ and $Z n\left(F_{\text {dil }}>50\right)$ because target recoveries were fulfilled and $=R_{\gamma} 1$ could be used in Eq. (1). Otherwise matrix effects were found for $F e\left(F_{d i l}\right.$ $=25), \mathrm{Mg}\left(\mathrm{F}_{\text {dil }}=2.5\right), \mathrm{Mn}\left(\mathrm{F}_{\mathrm{dil}} \leq 10\right)$ and $\mathrm{Ti}\left(\mathrm{F}_{\mathrm{dil}}=1\right)$ and $\bar{R}_{\gamma}$ values used in Eq. (1) were those reported Table 4.

\subsection{Precision}

Measurement repeatability of the overall procedure was estimated from duplicate analysis of aluminum alloys, which instrumental signal was higher than $\gamma_{\mathrm{LOQ}}$ values and $s_{r}^{\text {rel }}$ given by Eq. (2).

$s_{r}^{r e l}=\frac{s\left(A_{j}^{r e l}\right)}{\sqrt{2}}$

A target relative standard deviation was stated based on the relative acceptance criterion of 0.10 for amplitude

Table 4 Spike recoveries for matrix influence on atomic absorption measurements

\begin{tabular}{llll}
\hline Element & $F_{\text {dil }}$ & $\begin{array}{l}\text { Spike } \\
\left(\mathrm{mg} \mathrm{L}^{-1}\right)\end{array}$ & $\bar{R}_{\gamma} \pm s$ \\
\hline Chromium & 1 & 0.5 and 1.0 & $0.974 \pm 0.003$ \\
Copper & 50 and 250 & 0.2 and 0.4 & $0.996 \pm 0.032$ \\
Iron & 25 & 0.5 and 1.0 & $0.891 \pm 0.016$ \\
Magnesium & 2.5 & 0.05 and 0.1 & $0.731 \pm 0.014$ \\
& 10 & 0.05 and 0.1 & $0.101 \pm 0.020$ \\
Manganese & 25 & 0.1 & $0.101 \pm 0.021$ \\
& $10 ; 5$ and 2 & 0.2 & $0.838 \pm 0.022$ \\
Silicon & 1 & 10 and 20 & $0.975 \pm 0.082$ \\
Titanium & 1 & 5 and 10 & $0.779 \pm 0.021$ \\
Zinc & 625 & 0.05 and 0.1 & $0.960 \pm 0.024$ \\
& & 0.125 and 0.25 & \\
\hline
\end{tabular}

$\bar{R}_{\gamma}=\left(\gamma_{\mathrm{M}+\mathrm{sp}}-\gamma_{\mathrm{sp}}\right) / \gamma_{\mathrm{sp}}$ ranges and taking into account the definition of limit of repeatability for duplicated sets at a coverage probability of approximately $95 \%$ [26]. In this conditions $s_{r}(t g)^{r} e l=0.1 / 2.8=0.04$. Table 4 presents duplicate ranges and $s_{r}^{\text {rel }}$ values, which are adequate to the intended use of the results because $s_{r}^{\text {rel }} \leq s_{r(t g)}^{r e l}$.

Intermediate measurement precision expressed as relative standard deviation, $s_{\mid P}^{r e l}$, was estimated by Eq. (3), which associates $s_{r}^{\text {rel }}$ values, over a large mass fraction ranges, with $s_{Q C}^{r e l}$ values obtained as described in 3.1.

$s_{I P}^{r e l}=\sqrt{\left(s_{r}^{r e l}\right)^{2}+\left(s_{Q C}^{r e l}\right)^{2}}$

Target for $s_{I P}^{r e l}$ and $s_{I P(t g)^{\prime}}^{r e l}$, were also stated using Eq. (3) considering the corresponding ones. So, $s_{I P(t g)}^{r e l}=0.068$ for $\mathrm{Cr}$, Si and $\mathrm{Ti}$ and $s_{I P(t g)}^{r e l}=0.046$ for $\mathrm{Cu}, \mathrm{Fe}, \mathrm{Mg}, \mathrm{Mn}$ and $\mathrm{Zn}$ were obtained. From Table 2 all target values were fulfilled.

\subsection{Trueness}

The comparison of the obtained measurement CRM values with the certified ones follows the application note 1 of the European Reference Materials [25]. In this approach the difference $\Delta=\left|w_{C R M}-\bar{w}_{C R M}^{\text {obs }}\right|$, was compared with $U_{\Delta}$ given by:

$U_{\Delta}=2 \sqrt{u\left(w_{\mathrm{CRM}}\right)^{2}+u\left(\bar{w}_{\mathrm{CRM}}^{\mathrm{obs}}\right)^{2}}$

Standard uncertainty of $w_{\text {CRM }}$ reported in the NIST SRM 87a certificate has no information about the coverage factor, $k$. So, $k=1$ was used. Once none of $u\left(w_{C R M}\right)$ values reported were available for BCS $181 / 1$ it was adopted those from the certificate of the BCS 181/3, dated of 2013. In case of BCS No 268 and $N^{\circ} 300 u\left(w_{C R M}\right)$ values were calculated by Eq. (5) because those certificates only report the individual results of participants. The Eq. (5) was also used to obtain $u\left(\bar{w}_{C R M}^{\text {obs }}\right)$ values from experimental values. As shown in Table 5 , in all situations $<\Delta<U_{\Delta}$ for a confidence level of around 0.95 and no significant differences among the measurement results and the certified values were found.

$u\left(w_{C R M}\right) \frac{s}{\sqrt{n}}$

Mean recovery from CRM analysis was calculated by Eq. (6) while $u(\bar{R})$, by Eq. (7), because CRM analysis was performed on intermediate precision conditions 
Table 5 Comparison of measurement results with the certified values

\begin{tabular}{|c|c|c|c|c|c|c|c|}
\hline Elements & CRM & $w_{\text {CRM }}$ & $u\left(w_{\mathrm{CRM}}\right)$ & $\bar{w}_{\text {CRM }}^{\text {obs }}$ & $u\left(\bar{w}_{\mathrm{CRM}}^{\mathrm{obs}}\right)$ & $\Delta$ & $U(\Delta)$ \\
\hline \multirow[t]{2}{*}{$\mathrm{Cr}$} & SRM 87a & 0.11 & 0.01 & 0.12 & $0.003^{b}$ & 0.006 & 0.02 \\
\hline & BCS N. ${ }^{\circ} 300$ & 0.15 & 0.003 & 0.16 & $0.005^{\mathrm{b}}$ & 0.007 & 0.01 \\
\hline \multirow[t]{4}{*}{$\mathrm{Cu}$} & SRM 87a & 0.30 & 0.01 & 0.30 & $0.01^{\mathrm{a}}$ & 0.003 & 0.02 \\
\hline & BCS-CRM N.o 181/1 & 3.99 & 0.027 & 3.93 & $0.08^{\mathrm{a}}$ & 0.06 & 0.18 \\
\hline & BCS n. ${ }^{\circ} 268$ & 1.34 & 0.006 & 1.37 & $0.05^{b}$ & 0.03 & 0.10 \\
\hline & BCS N. ${ }^{\circ} 300$ & 1.28 & 0.007 & 1.30 & $0.03^{\mathrm{a}}$ & 0.02 & 0.06 \\
\hline \multirow[t]{4}{*}{$\mathrm{Fe}$} & SRM 87a & 0.61 & 0.02 & 0.60 & $0.02^{b}$ & 0.01 & 0.06 \\
\hline & BCS-CRM N. ${ }^{\circ} 181 / 1$ & 0.36 & 0.004 & 0.35 & $0.01^{\mathrm{a}}$ & 0.01 & 0.02 \\
\hline & BCS n. ${ }^{\circ} 268$ & 0.39 & 0.004 & 0.40 & $0.01^{b}$ & 0.01 & 0.03 \\
\hline & BCS N. ${ }^{\circ} 300$ & 0.30 & 0.004 & 0.31 & $0.01^{b}$ & 0.01 & 0.02 \\
\hline \multirow[t]{4}{*}{$\mathrm{Mg}$} & SRM 87a & 0.37 & 0.01 & 0.37 & $0.01^{\mathrm{a}}$ & 0.002 & 0.034 \\
\hline & BCS-CRM N.o 181/1 & 1.42 & 0.01 & 1.37 & $0.03^{\mathrm{a}}$ & 0.05 & 0.06 \\
\hline & BCS n. ${ }^{\circ} 268$ & 0.56 & 0.01 & 0.53 & $0.01^{a}$ & 0.027 & 0.028 \\
\hline & BCS N. ${ }^{\circ} 300$ & 2.76 & 0.01 & 2.71 & $0.07^{\mathrm{a}}$ & 0.05 & 0.15 \\
\hline \multirow[t]{4}{*}{$\mathrm{Mn}$} & SRM 87a & 0.26 & 0.01 & 0.26 & $0.005^{\mathrm{a}}$ & 0.004 & 0.022 \\
\hline & BCS-CRM N. ${ }^{\circ} 181 / 1$ & 0.10 & 0.002 & 0.10 & $0.001^{\mathrm{a}}$ & 0.002 & 0.005 \\
\hline & BCS n. ${ }^{\circ} 268$ & 0.22 & 0.003 & 0.21 & $0.0004^{a}$ & 0.005 & 0.006 \\
\hline & BCS N. ${ }^{\circ} 300$ & 0.41 & 0.003 & 0.41 & $0.01^{\mathrm{a}}$ & 0.003 & 0.022 \\
\hline \multirow[t]{3}{*}{$\mathrm{Si}$} & SRM 87a & 6.24 & 0.03 & 6.29 & $0.06^{\mathrm{a}}$ & 0.05 & 0.14 \\
\hline & BCS-CRM N.o 181/1 & 0.38 & 0.01 & 0.38 & $0.02^{\mathrm{a}}$ & 0.001 & 0.043 \\
\hline & BCS n. ${ }^{\circ} 268$ & 4.85 & 0.02 & 4.77 & $0.06^{\mathrm{a}}$ & 0.08 & 0.12 \\
\hline \multirow[t]{3}{*}{$\mathrm{Ti}$} & SRM 87a & 0.18 & 0.010 & 0.18 & $0.002^{\mathrm{a}}$ & 0.004 & 0.020 \\
\hline & BCS-CRM N.o 181/1 & 0.14 & 0.001 & 0.13 & $0.01^{\mathrm{a}}$ & 0.009 & 0.012 \\
\hline & BCS N. ${ }^{\circ} 300$ & 0.15 & 0.002 & 0.15 & $0.003^{\mathrm{a}}$ & 0.005 & 0.008 \\
\hline \multirow[t]{4}{*}{$\mathrm{Zn}$} & SRM 87a & 0.16 & 0.01 & 0.16 & $0.003^{\mathrm{a}}$ & 0.004 & 0.021 \\
\hline & BCS-CRM N. ${ }^{\circ} 181 / 1$ & 0.02 & 0.0001 & 0.02 & $0.001^{\mathrm{a}}$ & 0.001 & 0.017 \\
\hline & BCS n. ${ }^{\circ} 268$ & 0.05 & 0.001 & 0.05 & $0.001^{a}$ & 0.0005 & 0.002 \\
\hline & BCS N. ${ }^{\circ} 300$ & 5.98 & 0.013 & 5.99 & $0.04^{\mathrm{a}}$ & 0.011 & 0.078 \\
\hline
\end{tabular}

${ }^{\mathrm{a}} \bar{W}_{\text {CRM }}^{\text {obs }}$ given by Eq. (5)

${ }^{\mathrm{b}} \bar{W}_{\mathrm{CRM}}^{\mathrm{Cbs}}=\frac{0.10 \times \bar{w}_{\mathrm{CRM}}^{\mathrm{obs}}}{2 \sqrt{3}}, U(\Delta)$ given by Eq. (4) for $k=2 ; p \sim 0.05$ quantifying the combination of pure random effects with the variation between run systematic effects [10].

$\bar{R}_{C R M}=\sum_{i=1}^{N} \frac{\bar{w}_{C R M}^{o b s}}{w_{C R M}}$

$u\left(\bar{R}_{C R M}\right)=\frac{1}{N} \sqrt{\sum_{i=1}^{N}\left[R_{C R M}^{2}\left(\left(\frac{u\left(\bar{w}_{C R M}^{\text {obs }}\right)}{\bar{w}_{C R M}^{\text {obs }}}\right)^{2}+\left(\frac{u\left(w_{C R M}\right)}{w_{C R M}}\right)^{2}\right)\right]}$

Table 3 shows the mean recovery and $u\left(\bar{R}_{C R M}\right)$ values calculated using data of Table 5. Previously target values for recovery were defined considering the acceptance criteria: $0.90 \leq R \leq 1.00$. Using the $t$ statistic significance test [24], as shown in Table 2, it can be established that mean recoveries of CRM analysis were metrologically equivalent to 1 for a level of confidence of approximately $95 \%$, because $\leq t_{c a l} 2$, being two the coverage factor [8]. Additionally a target value of 0.058 for $u\left(\bar{R}_{C R M}\right)$ can be considered taking into account the acceptance criteria and assuming a rectangular distribution.

\subsection{Measurement uncertainty}

Measurement uncertainty of the results was estimated combining precision and trueness uncertainty components. This model is based on the concept that accuracy comprises precision plus trueness and that relative combined standard uncertainty, $u_{c}^{r e l}(w)$, comprises the two main components of uncertainty budget: intermediate precision and recovery according to Eq. (8) [8-10]. 
$u_{\mathrm{c}}^{\mathrm{rel}}(\mathrm{w})=\sqrt{u\left(s_{I P}^{\mathrm{rel}}\right)^{2}+u\left(\bar{R}_{C R M}\right)^{2}}$

Combining the target values of the uncertainty components of Eq. (8), reported before, target values for combined uncertainty were stated. For $\mathrm{Cr}$, Si and $\mathrm{Ti}, u_{\mathrm{c}_{-} \mathrm{tg}}^{\mathrm{rel}}=0.089$ and for $\mathrm{Cu}, \mathrm{Fe}, \mathrm{Mg}, \mathrm{Mn}$ and $\mathrm{Zn}=u_{\mathrm{c}_{-} \mathrm{tg}}^{\mathrm{rel}} 0.074$ were obtained. These two groups were differentiated because $s_{Q C(t g)}^{\text {rel }}$ values were higher for $\mathrm{N}_{2} \mathrm{O}-\mathrm{C}_{2} \mathrm{H}_{2}$ flame than air- $\mathrm{C}_{2} \mathrm{H}_{2}$ one. Table 3 summarizes $u_{c}^{\text {rel }}(w)$ values for the alloying elements and the target ones were fulfilled.

The relative expanded uncertainty values were obtained multiplying $u_{c}^{\text {rel }}(w)$ (Table 6 ) by a coverage factor of 2, for a confidence level of approximately $95 \%$ [7].

Results of metals in aluminum alloys with the associated expanded uncertainty in non-ferrous fraction from auto-shredders, are shown in Table 5 as example, following the described validation and quality control actions, which assures confidence in both measurement procedures used and the results obtained.

\section{Conclusion}

In this work the analytical performance characteristics of the procedures were determined setting up validation and quality control actions in the characterization of the relevant alloying elements of aluminum alloys $(\mathrm{Si}, \mathrm{Mg}, \mathrm{Cu}, \mathrm{Zn}$, $\mathrm{Mn}, \mathrm{Ti}, \mathrm{Fe}$ and $\mathrm{Cr}$ ). The results proved the approach of sorting aluminum alloys based on its chemical composition. Summarizing: two different acid digestion mixtures were used: an $\mathrm{HCl}-\mathrm{HNO}_{3}$ acid mixture for $\mathrm{Mg}, \mathrm{Cu}, \mathrm{Zn}, \mathrm{Mn}, \mathrm{Ti}, \mathrm{Fe}$ and $\mathrm{Cr}$ analysis and $\mathrm{HCl}-\mathrm{HNO}_{3}$ - $\mathrm{HF}$ mixture followed by $\mathrm{HF}$ complexation using $\mathrm{H}_{3} \mathrm{BO}_{3}$ for silicon due to the chemical behaviour of silicon; linear calibration function for $\mathrm{Cr}, \mathrm{Cu}$, $\mathrm{Fe}, \mathrm{Mn}, \mathrm{Si}, \mathrm{Zn}$ and second order function for $\mathrm{Mg}$ and $\mathrm{Ti}$ were defined using Mandel fitting test; stability of calibration functions performance over the analysis as QC warranted by the fulfilling of the target relative errors for $\gamma_{\mathrm{QC}}$ within \pm 0.05 of the expected values for $\mathrm{Cu}, \mathrm{Fe}, \mathrm{Mg}, \mathrm{Mn}$ and $\mathrm{Zn}$ (air- $\mathrm{C}_{2} \mathrm{H}_{2}$ flame) and \pm 0.10 for $\mathrm{Cr}, \mathrm{Si}$ and $\mathrm{Ti}$ $\left(\mathrm{N}_{2} \mathrm{O}-\mathrm{C}_{2} \mathrm{H}_{2}\right.$ flame); matrix difference between the acid digestion solutions and $\mathrm{CS}$ were not found for $\mathrm{Cr}, \mathrm{Cu}, \mathrm{Mn}$, $\mathrm{Mg}$, $\mathrm{Si}$ and $\mathrm{Zn}\left(R_{\gamma}=1\right)$, while for $\mathrm{Fe}\left(\mathrm{F}_{\mathrm{dil}}=25\right), \mathrm{Mg}\left(\mathrm{F}_{\mathrm{dil}}=2.5\right)$, $\mathrm{Mn}\left(\mathrm{F}_{\mathrm{dil}} \leq 10\right)$ and $\mathrm{Ti}\left(\mathrm{F}_{\mathrm{dil}}=1\right) \bar{R}_{\gamma}$ values used are those reported in Table 4; repeatability from duplicates were adequate to purpose because $s_{r}^{\text {rel }} \leq s_{r(t g)}^{\text {rel }}($ Table 4); no bias were found from CRM's analysis (Tables 4 and 5 ) and measurement uncertainty of the results was estimated combining overall precision and trueness uncertainty components based on the concept that accuracy combines these two components.

Table 7 shows the typical mass fraction ranges of the discriminating elements of the most common Al wrought and cast alloys, by series. Silicon was the element that allows the differentiation between cast and wrought alloys. In case of cast alloy silicon discriminates series 400 with highest mass fractions. The only wrought alloys having high Si mass fractions are the 4000 series, but these are rarely found.

For wrought alloys manganese is the discriminating element for series 3000 while for series 5000 it is also Mg. For series 6000 only $\mathrm{Mg}$ is relevant, but with lowest levels than 5000 ones, while for series 7000 is $\mathrm{Mg}$ and Zn. Series 1000 has low content of all alloying elements. The adequacy of the procedures to the low mass fractions were evaluated using the uncertainty information in compliance assessment [28]. For instances for silicon the $w_{L O Q}$ values is $0.15 \mathrm{~g} / 100 \mathrm{~g}$ (Table 3), which fulfills the compliance with the upper limit of $0.2 \mathrm{~g} / 100 \mathrm{~g}$ (Table 7) because these value is lower than the acceptance limit of $0.19 \mathrm{~g} / 100 \mathrm{~g}$ calculated as $\left[0.2-1,65 \times u_{c}\right]$ being 1,65 the one tailed $t$ value at $95 \%$ confidence and $u_{c}$ given in Table 3 . The same is true when comparing the $w_{L O Q}$ values (Table 3 ) with the calculated acceptance limits for $\mathrm{Mg}, \mathrm{Cu}$ and $\mathrm{Zn}$ of $(0.19 \mathrm{~g}$ $/ 100 \mathrm{~g}$ ) and $0.18 \mathrm{~g} / 100 \mathrm{~g}$ for $\mathrm{Mn}$, which also shows that the
Table 6 Mass fraction composition of aluminum alloys of non-ferrous fraction of auto-shredders

\begin{tabular}{lccccc}
\hline Parameter & $\begin{array}{l}\text { Range } \\
{[\mathrm{g} /(100 \mathrm{~g})]}\end{array}$ & \multicolumn{2}{l}{$w \pm U(w),[\mathrm{g} /(100 \mathrm{~g}]$} & \\
\cline { 3 - 6 } & & Sample 1 & Sample 2 & Sample 3 & Sample 4 \\
\hline $\mathrm{Cr}$ & $0.04-1.6$ & $0.0921 \pm 0.010$ & $0.0389 \pm 0.0044$ & $0.0152 \pm 0.0017$ & $0.0179 \pm 0.0020$ \\
$\mathrm{Cu}$ & $0.05-3$ & $0.161 \pm 0.011$ & $2.95 \pm 0.21$ & $2.51 \pm 0.18$ & $0.220 \pm 0.015$ \\
$\mathrm{Fe}$ & $0.3-1$ & $0.250 \pm 0.024$ & $0.927 \pm 0.089$ & $0.914 \pm 0.088$ & $0.941 \pm 0.090$ \\
$\mathrm{Mg}$ & $0.1-2.5$ & $0.562 \pm 0.045$ & $0.126 \pm 0.010$ & $0.335 \pm 0.027$ & $0.191 \pm 0.015$ \\
$\mathrm{Mn}$ & $0.004-0.3$ & $0.0695 \pm 0.0092$ & $0.310 \pm 0.041$ & $0.178 \pm 0.023$ & $0.190 \pm 0.025$ \\
$\mathrm{Si}$ & $0.1-8$ & $0.423 \pm 0.029$ & $7.27 \pm 0.49$ & $9.62 \pm 0.65$ & $12.25 \pm 0.83$ \\
$\mathrm{Ti}$ & $0.01-0.1$ & $0.0248 \pm 0.0032$ & $0.0608 \pm 0.0078$ & $0.0449 \pm 0.0058$ & $0.0271 \pm 0.0035$ \\
$\mathrm{Zn}$ & $0.02-2.1$ & $0.0147 \pm 0.0012$ & $0.865 \pm 0.073$ & $1.19 \pm 0.10$ & $0.276 \pm 0.023$ \\
\hline
\end{tabular}

$w$ mass fraction given by Eq. (1), $U(w)$ expanded uncertainty of $w,(k=2 ; p \sim 0.95)$ 


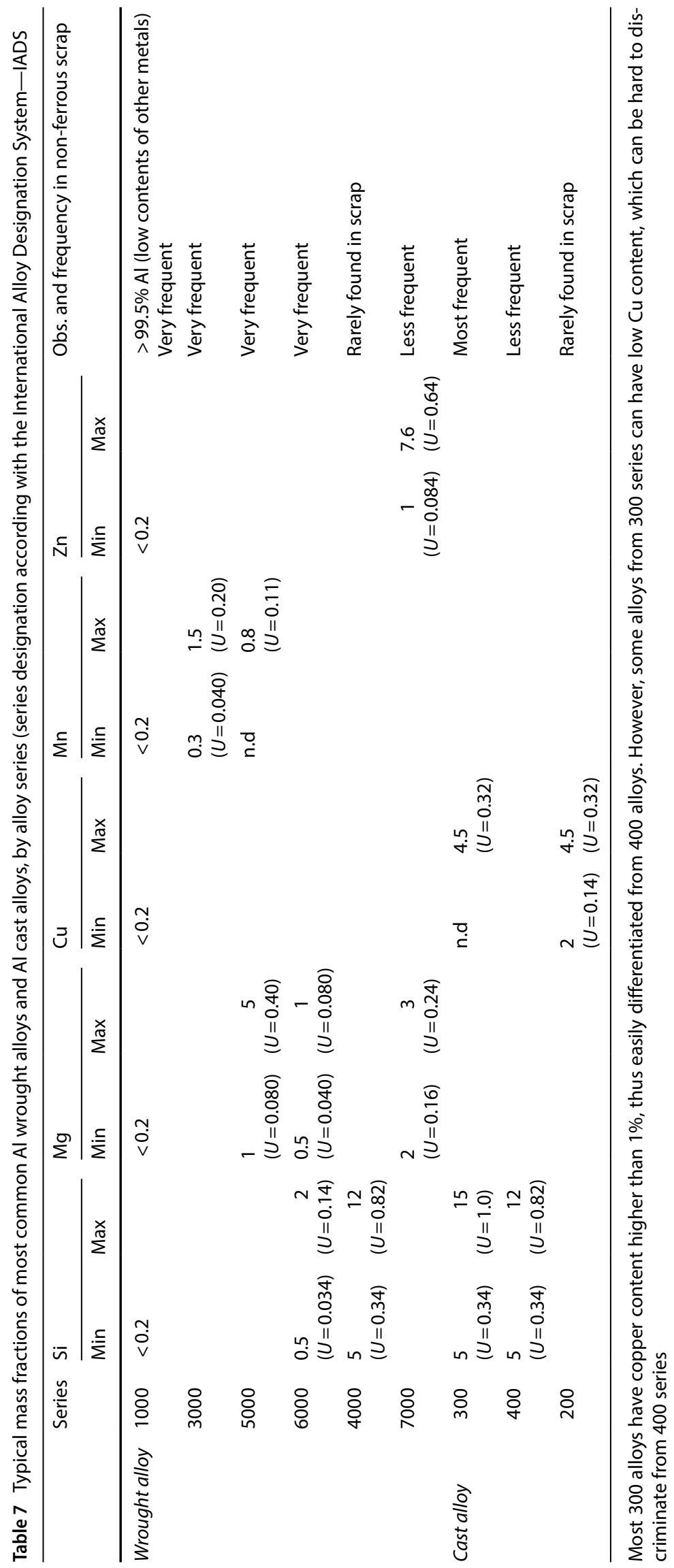


procedures and both quality control actions and targets used were adequate for these elements.

In case of cast alloy series 200 copper is the discriminating and for series 300 is $\mathrm{Si}$ and $\mathrm{Cu}$.

Measurement uncertainty gives the quality of the result and defines the numerical expression of results. If expanded uncertainty is given, no more than two significant digits for reporting uncertainty is recommended and the results should be rounded to be consistent with the provided uncertainty. As can be seen from Tables 6 and 7 , with the $U$ values reported becomes clear that the figures of the limit values are not affected by uncertainty.

The results obtained in this investigation were very useful for design of the separation devices within the Shreddersor project, and we believe it will also be quite relevant for the scrap recycling industry, at various levels, in the perspective of the application of the sorting operations to aluminum alloy fragments: (a) firstly, the possibility of accurately analyzing the main alloying elements is demonstrated, with the proposed procedures, in order to identify the main alloys present in the scrap, allowing the stakeholders to have reliable information on the materials they deal with; secondly, it will also allow recyclers to design and operate sorting operations according with the material feed, to identify precisely the separated alloys, and to quantify the separation efficiencies and the purity of the fractions they produce.

Acknowledgements The work here presented is included in the European project ShredderSort (Grant Agreement Nr. 603676, FP7 Theme ENV.2013.6.3-1; ENV.2013.6.2-3, collaborative projects). The authors wish to acknowledge the financial support of the European Commission. The authors acknowledge Jorgiana Branco from LNEG for providing the digestion procedures during the research.

\section{Compliance with ethical standards}

Conflict of interest The authors declare that they have no competing interests.

\section{References}

1. Margarido $F$, Nogueira CA, Novais Santos R, Durão F, Guimarães C; Trancoso MA, Oliveira PC, Pedrosa F, Gonçalves AM (2015) Evaluation of main aluminum alloys in non-ferrous fraction of auto-shredder recycling process, in M2D2015-6th International conference on mechanics and materials in design (Proc), Ponta Delgada, Açores, Portugal, 2015, J. F. Silva Gomes, S. A. Meguid, (Eds), 2033-2038

2. Nogueira CA, Trancoso MA, Pedrosa F, Crujeira AT, Oliveira PC, Gonçalves AM, Margarido F, Novais Santos R, Durão F, Guimarães $C$ (2015) The role of automated sorting in the recovery of aluminum alloys waste. In: Vilarinho C, Castro F, Russo M (eds) WASTES: Solutions, Treatments and Opportunities. CRC PressTaylor \& Francis, London, UK
3. Hatayama H, Daigo I, Matsuno Y, Adachi Y (2012) Evolution of aluminum recycling initiated by the introduction of next-generation vehicles and scrap sorting technology. Resour Conserv Recy 66:8-14

4. Flame Atomic Absorption Spectrometry, Analytical Methods, Fourteenth edition, Agilent Technologies Australia (M) Pty, Ltd. (2017) https://www.agilent.com/cs/library/usermanuals/publi c/0009.pdf Accessed 02 mar 2018

5. Teixeira P, Calisto S, Lopes H (2015) Trancoso MA. Accred Qual Assur 20:67-74

6. Joint Committee for Guides in Metrology (2012) International vocabulary of metrology - basic and general concepts and associated terms (VIM). BIPM, Sèvres

7. ISO 11352 (2012) Water quality-estimation of measurement uncertainty based on validation and quality control data. International Organization for Standardization, Geneva, $\mathrm{CH}$

8. Barwick VJ, Ellison SLR (2000) VAM project 3.2.1-part (d) protocal for uncertainty evaluation data. LGC, London

9. Trancoso I, Roseiro LB, Martins PL, Trancoso MA (2009) Validation and quality assurance applied to goat milk chemical composition: Minerals and trace elements measurements. Dairy Sci Technol 89:241-256

10. Cordeiro RMS, Rosa CMG, Silva RJNB (2018) Measurements recovery evaluation from the analysis of independent reference materials: analysis of different samples with native quantity spiked at different levels. Accred Qual Assur 23:57-71

11. Alves S, Correia dos Santos MM, Trancoso MA (2009) Accred Qual Assur 14:87-93

12. Trancoso MA, Sousa A, Mouro F, Freitas MC, Almeida S, Canha N (2012) Accred Qual Assur 17:199-206

13. Thermo Fisher Scientific (2008) Atomic Absorption Spectrometry Methods Manual, 949940030011 , Issue 5

14. American Public Health Association (APHA) (2017) Standard methods for the examination of water and wastewater, 23rd edn. American Public Health Association, Washington, DC

15. ISO 8466-1 (1990) Water quality - Calibration and evaluation of analytical methods and estimation of performance characteristics. Part 1: Statistical evaluation of the linear calibration function. International Organization for Standardization Geneva, $\mathrm{CH}$

16. ISO 8466-2 (2001) Water quality - Calibration and evaluation of analytical methods and estimation of performance characteristics - Part 2: Calibration strategy for non-linear second-order calibration functions. International Organization for Standardization, Geneva, $\mathrm{CH}$

17. Trancoso MA, Correia dos Santos MM, Gonçalves MLS (2003) Quality assurance program for the chemical characterization of soils. Accredit Qual Assur 8:323-333

18. Subramanian G (ed) (1995) Quality Assurance in environmental monitoring - instrumental methods. New York, VCH, Weinheim

19. Welz B, Sperling M (1999) Atomic absorption spectrometry. Wiley_VCH, Weinheim

20. OTTO M (1998) Multivariate methods. In: Kellner R, Mermet $\mathrm{JM}$, Otto M, Widmer HM (eds) Analytical chemistry. Wiley-VCH, Weinheim

21. Miller J, Miller J (2005) Statistics and chemometrics for analytical chemistry, 5th edn. Pearson, London

22. IUPAC (1978) Nomenclature symbols units and their usage in spectrochemical analysis-II. Spectromchim Acta. https://doi. org/10.1016/0584-8547(78)80043-3

23. Currie LA (1995) Nomenclature en evaluation of analytical methods, including detection and quantification capabilities (IUPAC recommendations 1995). Pure Appl Chem 67:1699-1723

24. F. B. Magnusson and U. Örnemark (eds.) Eurachem Guide: The fitness for purpose of analytical methods - a laboratory guide to method validation and related topics, (2nd ed. 2014). ISBN 
978-91-87461-59-0. Available from https://www.eurachem. org Accessed 12 jan 2018

25. Linsinger $T$ (2005) Comparison of a measurement result with thecertified value, application note 1. European reference materials, Geel. https://ec.europa.eu/jrc/sites/defaul Accessed 12 jan 2018

26. ISO 5725-1 (1994) Accuracy (trueness and precision) of measurement methods and results-part 1 General principles and definitions. ISO, Geneva

27. Eurachem/CITAC Guide (2012) Quantifying uncertainty in analytical measurement, 3rd edn. In: Ellison SRL, Williams A (eds).ISBN: 978-0-948926-30-3. https://www.eurachem.org. Accessed 12 jan 2018
28. S L R Ellison and A Williams (Eds). Eurachem/CITAC guide: Use of uncertainty information in compliance assessment. (First Edition (2007). Available from www.eurachem.org." Accessed 22 jun 2020

Publisher's Note Springer Nature remains neutral with regard to jurisdictional claims in published maps and institutional affiliations. 